\title{
EFISIENSI PEMBERIAN PAKAN BENIH IKAN BAWAL BINTANG (TRACHINOTUS BLOCHII) DENGAN MENGGUNAKAN PAKAN ALAMI ROTIFERA(BRACHIONUS PLICATILIS)
}

\section{Efficiency of Feeding Snubnose Pompano (Trachinotus blochii) Seeds Using Natural Feed of Rotifers (Brachionus plicatilis)}

Yoga Lambang Imani ${ }^{1}$, Seto Sugianto Prabowo Rahardjo ${ }^{1}$, Nailul Izzah $^{1}$, Muhammad Hidayat ${ }^{2}$ dan Rani Yuwanita $^{1}$

${ }^{1}$ Program Studi Budidaya Perairan, Fakultas Perikanan dan Ilmu Kelautan, Universitas Brawijaya, Malang

${ }^{2}$ Balai Perikanan Budidaya Laut (BPBL) Lombok, Lombok

*seto.wre@ub.ac.id

\section{Abstrak}

Ikan bawal bintang (Trachinotus blochii) merupakan komoditas laut yang memiliki nilai ekonomis tinggi. Bawal bintang (T. blochii) merupakan spesies budidaya perikanan laut yang terbilang masih baru di Indonesia. Permintaan terhadap ikan ini terus meningkat terutama dari pasar internasional seperti Singapura, Taiwan, Hong Kong, dan China.Agar populasi tetap seimbang untuk itu dilakukan kegiatan budidaya agar kebutuhan masyarakat tetap terpenuhi.Balai Perikanan Budidaya Laut (BPBL) Lombok merupakan balai budidaya yang menerapkan pemberian pakan rotifera untuk pembenihan ikan bawal bintang (T. blochii),Dengan diberikan rotifera diharapkan pada benih bawal bintang dapat tumbuh dengan cepat dan terpenuhi nutrisi larva,sehingga didapatkan pertumbuhan yang cepat.

Kata kunci : Bawal bintang, Pembenihan, Rotifera

\section{Abstract}

Snubnose pompano (Trachinotus blochii) is a marine commodity that has high economic value. Star pomfret (T. blochii) is a relatively new species of aquaculture in Indonesia. Demand for these fish continues to increase, especially from international markets such as Singapore, Taiwan, Hong Kong, and China. For the population to remain balanced for this, aquaculture activities are carried out so that the needs of the community remain fulfilled. rotifera feed for hatchery of star pomfret (T. blochii), With the introduction of rotifers, it is expected that the starfruit seeds can proliferate and fulfill the nutrients of the larvae so that rapid growth is obtained.

Keywords: Snubnose pompano, Hatchery, Rotifers

\section{PENDAHULUAN}

Menurut Fahmawati (2014), pertumbuhan ikan bawal bintang yang termasuk cepat dan mempunyai harga pasar yang baik adalah potensi yang tepat untuk melakukan budidaya di Asia-Pasifik. Harga ikan bawal bintang yang tinggi mendorong usaha penangkapan di alam terus meningkat sehingga dapat menyebabkan kerusakan kelestarian populasi ikan bawal bintang.

Kerusakan tersebut dikarenakan cara penangkapan yang kurang tepat untuk melakukan penangkapan di alam. Ada peluang pasar domestik dan ekspor yang cukup tinggi, maka perlu dilakukan usaha budidaya yang mencakup pembenihan ikan bawal bintang.

Brachionus termasuk filum Rotifera, kelas Monogononta, bangsa Ploima, suku Brachionidae, marga Brachionus, jenis Brachionus plicatilis. Rotifera mempunyai warna putih dan berbentuk seperti piala, pada bagian korona atau mulut dilengkapi dengan bulu getar yang bergerak aktif. Diameter korona antara 60-80 mikron. Tubuh rotifera terbagi atas 3 bagian yaitu kepala, badan dan
Diterima/submitted:16 Mei 2019

Disetujui/accepted:28 Juni 2019 
kaki atau ekor. Pemisahan bagian kepala dengan badan tidak jelas. Bagian kaki dan ekor berakhir dengan belahan yang disebut jari. Badan rotifera dilapisi kutikula yang tebal disebut "lorika". Pada bagian kepala terdapat 6 duri, sepasang di tengah sebagai duri yang panjang. Ujung depan tubuh rotifera dilengkapi dengan gelang-gelang silia yang kelihatan melingkar seperti spiral yang disebut "korona" dan berfungsi untuk memasukkan makanan ke dalam mulut (Gopalakrishnan, 2014).

Tinggi persentase produksi tersebut juga selaras dengan terus meningkat harga pakan untuk kegiatan pembenihan ikan bawal bintang. Untuk mengimbangi nilai nutrisi pakan pelet yaitu dengan cara menggunakan pakan tambahan atau pakan alami. Penggunaan pakan alami sendiri juga harus melihat beberapa aspek dalam kegiatan budidaya agar kegiatan budidaya tetap bernilai ekonomis namun kelestarian lingkungan tetap terjaga atau tidak merusak media hidup ikan bawal bintang. Hai itu di lain sisi untuk menambah nutrisi dan daya tumbuh kembang benih dengan menggunakan pakan alami berupa rotifera.

Jumlah dan kualitas makanan rotifera sangat mempengaruhi populasi rotifera. Hasil penelitian menyebutkan bahwa kepadatan Tetraselmis dan Chlorella sebesar 5 juta $\mathrm{sel} / \mathrm{ml}$ dan ragi roti sebanyak 1-2 g/berat badan/1 juta rotifera akan diperoleh rotifera sebanyak 500-700 ekor/ml selama 3 minggu dengan inokulasi awal 10 ekor/ml. Oleh sebab itu untuk mendapatkan rotifera yang lebih baik disarankan agar dalam memberikan pakan Chlorella dengan kepadatan 2,13-3,5 juta sel/ml (Rachmasari, 1989).

Menurut Lubzens et al. (1989), keunggulan yang dimiliki rotifera ialah ukuran yang relatif kecil, berenang secara lambat sehingga mudah dimangsa larva, dan mudah dicerna. Rotifera sangat mudah untuk dikembangbiakkan dan mempunyai gizi yang cukup tinggi serta diperkaya asam lemak dan antibiotik.

Balai Perikanan Budidaya Laut (BPBL) Lombok sudah mulai menerapkan pakan pengganti atau pakan tambahan alami dengan menggunakan rotifera (Brachionus plicatilis) sebagai pakan dengan harapan mampu menggantikan peran pakan pelet dalam kegiatan pembenihan ikan bawal bintang.

Rotifera didapatkan dari hasil budidaya berskala bak bervolume besar yang berada di tempat balai dan dapat dipanen bila sudah mencapai waktu 7 hari. Rotifera yang dipakai biasa dipanen di pagi hari atau saat pemberian pakan benih di waktu pagi. Metode panen harian rotifera dikultur dengan kepadatan 20 individu/ml kemudian dipanen pada hari ke-5 setelah mencapai kepadatan 100-150 individu sebanyak 30\% dari total kultur. Selanjutnya bak kultur rotifera diisi kembali dengan fitoplankton (kepadatan 3-4 juta $\mathrm{sel} / \mathrm{ml}$ ) pemanenan dilakukan dengan menggunakan plankton net 40 mikron dan disaring kembali dengan plankton net 250 mikron untuk memisahkan kotoran.

\section{METODOLOGI}

\section{Waktu dan Tempat}

Penelitian ini dilakukan pada bulan Juli 2018 di Balai Perikanan Budidaya Laut (BPBL), Desa Giligenting, Kecamatan Sekotong, Lombok, Nusa Tenggara Barat.

\section{Materi Penelitian}

Kegiatan pembenihan ikan bawal bintang menggunakan kolam beton berukuran 4 $\mathrm{m} \times 2,5 \mathrm{~m}$ x $1 \mathrm{~m}$. Pada Penelitian ini kolam yang akan digunakan untuk pembenihan merupakan kolam yang sudah mengalami siklus panen benih bawal bintang sebelumnya sehingga memerlukan pengolahan kolam. Selanjutnya kolam terlebih dahulu ditutup saluran inlet agar tidak ada air yang
Diterima/submitted:16 Mei 2019

Disetujui/accepted:28 Juni 2019 
masuk dan dibuka saluran outlet agar sisa-sia air dan kotoran terbuang semua. Kolam dibersihkan dengan cara menyikat permukaan kolam dari sisa kotoran, kemudian disiram menggunakan air bersih pada setiap sudut dan sisi kolam. Selanjutnya dilakukan pemberian kaporit agar sisa-sisa parasit mati dan kolam menjadi steril, setelah itu didiamkan selama 24 jam kemudian sisa kaporit yang menempel pada dinding kolam dibilas dengan air bersih sampai bau kaporit hilang, sehingga nanti tidak meracuni ikan pada saat pemeliharaan.

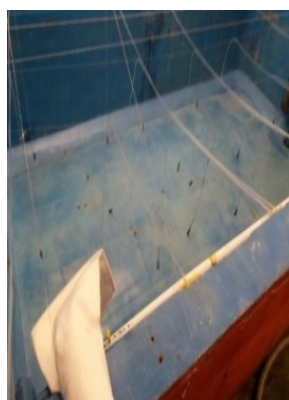

(a)

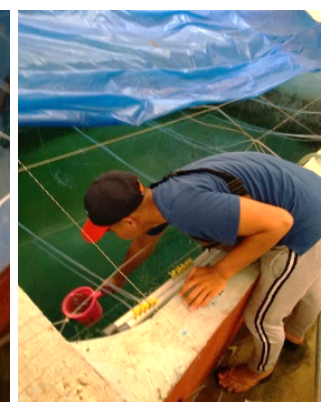

(b)

Gambar 1. (a) Pemberian kaporit; (b) Kolam yang sudah diberi kaporit.

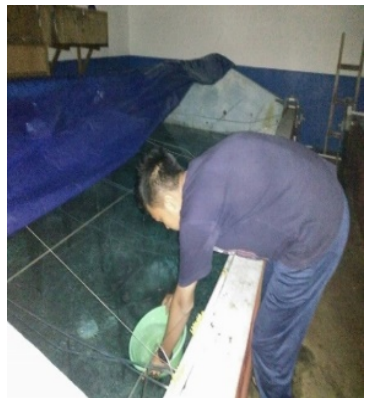

(a)

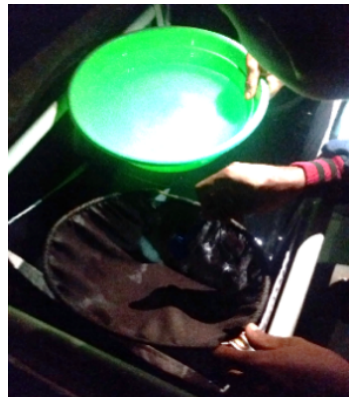

(b)

Gambar 2. (a) Proses pengambilan telur; (b) penebaran telur di kolam pembenihan.

\section{Prosedur Kerja \\ Penebaran telur}

Telur yang ditebar di BPBL Lombok berasal dari tempat sendiri yang melalui proses pemijahan induk bawal bintang yang berada di divisi pemeliharaan induk. Penebaran larva dilakukan pada malam hari. Larva berumur $\mathrm{D}_{0}$ yang baru menetas dipindahkan dengan memakai baskom dari bak penetasan menuju bak pemeliharaan larva yang berukuran $4 \mathrm{~m} \times 1,5 \mathrm{~m} \times 2 \mathrm{~m}$ dengan volume air $9 \mathrm{~m}^{3}$, kemudian larva ditebar dalam bak pemeliharaan larva
(Gambar 2). Jumlah larva yang ditebar sebanyak 21.700 ekor. Kepadatan larva dalam bak sebesar 1.808 ekor $/ \mathrm{m}^{2}$ dapat dilihat pada gambar 2, dan kemudian telur ditebar di kolam pembenihan. Penebaran telur dilakukan secara berhati-hati agar telur tidak pecah telur dipelihara di kolam benih sampai stadia larva D-30.

Menurut Juniyanto et al. (2008), pada saat larva ditebar dalam bak pemeliharaan, saluran inlet ditutup dan dipasang aerasi yang tidak terlalu besar pada sepuluh titik, hal ini dikarenakan larva bawal bintang memiliki

Diterima/submitted:16 Mei 2019
Disetujui/accepted:28 Juni 2019 
sifat seperti planktonis. Setelah larva bawal bintang ditebar, setelah itu saluran inlet dibuka dengan aliran kecil agar ikan tidak stres. Pemeliharaan larva berlang-sung selama 21 hari hingga layak untuk dipanen dan dipindahkan ke bak pendederan.

\section{Manajemen pemberian pakan}

Hal terpenting yang harus diperhatikan dalam pembenihan ikan bawal bintang adalah pakan harus sesuai dengan bukaan mulut larva dan cukup untuk memenuhi kebutuhan nutrisi. Pakan yang digunakan untuk pembenihan ikan bawal bintang pada penelitian ini menggunakan rotifera
(Brachionus plicatilis) karena rotifera mudah dibudidayakan dan mengandung nilai gizi yang tinggi untuk pertumbuhan larva. Jenis dan ukuran pakan larva disajikan pada Tabel 1.

Pakan diberikan dengan frekuensi 2 kali sehari, yaitu pagi pukul 09.00, serta sore pukul 15.00 WITA .Jenis rotifera yang digunakan sebagai pakan tambahan yaitu jenis (Brachionus plicatilis). Pemberian pakan dapat dilihat pada Gambar 3.

\section{Analisis Data}

Data yang didapat berupa tabel, gambar, dan penjelasan secara deskriptif.

Tabel 1. Jenis dan ukuran pakan larva.

\begin{tabular}{cccccc}
\hline Jenis Pakan & Jumlah & Ukuran & Waktu & Frekuensi & $\begin{array}{c}\text { Kandungan } \\
\text { Protein }\end{array}$ \\
\hline Nannochloropsis & $5 \times 10^{3} / \mathrm{ml}$ & $5-20 \mu \mathrm{m}$ & D3-15 & 1 kali/hari & $55,80 \%$ \\
Rotifera & $5-10 / \mathrm{ml}$ & $100-175 \mu \mathrm{m}$ & D3-20 & $1-2$ kali/hari & $35 \%-40 \%$ \\
Pelet & $\begin{array}{c}\text { Sesuai } \\
\text { kebutuhan }\end{array}$ & $0,31-0,48 \mathrm{~mm}$ & D17-30 & $5-7$ kali/hari & $48 \%$ \\
\hline
\end{tabular}

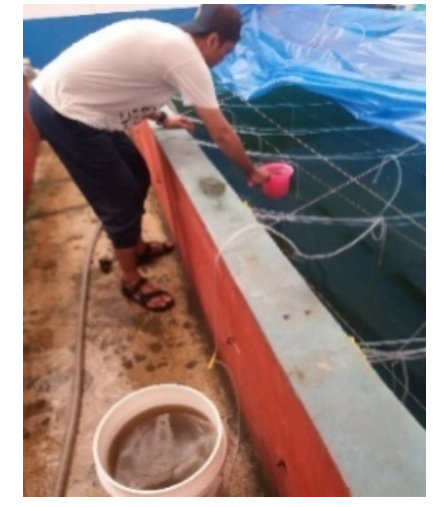

(a)

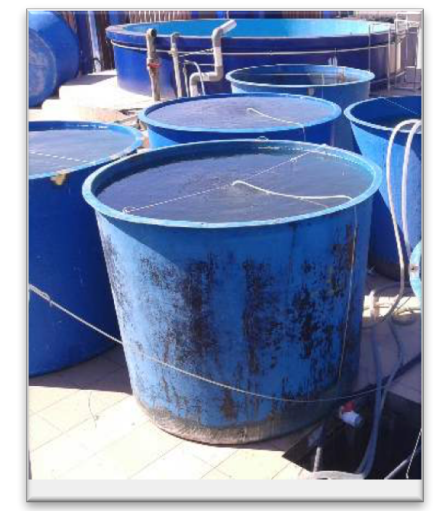

(b)

Gambar 3. (a) Pemberian rotifera; (b) bak kultur rotifera.

\section{HASIL DAN PEMBAHASAN}

Setelah semua metode penelitian dilakukan secara benar dan sistematik, selanjutnya didapatkan hasil penelitian pada kegiatan pembenihan ikan bawal bintang adalah sebagai berikut.

\section{FCR (Feed Conversion Ratio)}

FCR merupakan konversi pemberian pakan dalam istilah dapat di simpulkan seberapa banyak pakan yang dibutuhkan untuk menghasilkan $1 \mathrm{~kg}$ berat daging ikan. Pada penelitian ini didapatkan hasil FCR
Diterima/submitted:16 Mei 2019

Disetujui/accepted:28 Juni 2019 
dengan data jumlah pakan yang diberikan selama 40 hari sebesar 1.600 liter rotifera dengan rata-rata 20 liter/hari. FCR yang didapat pada penelitian ini yaitu 1,56 dengan awal padat tebar larva sebanyak 25.000 .

\section{SR (Survival Rate)}

SR merupakan kelulushidupan organisme budidaya dalam satuan persen. Hasil data panen lapang mendapatkan hasil sebanyak 17.850 ekor benih bawal bintang dari awal tebar sebanyak 25.000 larva. Pada penelitian ini didapatkan hasil SR sebesar 71 $\%$.

Sintasan atau kelangsungan hidup (Survival rate) ikan bawal bintang yang tinggi dapat mencapai $80 \%$ dikarenakan kolam budidaya yang terbuat dari beton. Hal ini terjadi karena pengawasan lebih mudah dan intensif (Juniyanto et al., 2008). Sehingga dapat disimpulkan hasil kelulushidupan ikan bawal bintang pada penelitian ini tergolong bagus.

\section{Kualitas air}

Hasil pengukuran suhu dan $\mathrm{pH}$ pada penelitian ini hasil sebagai berikut: suhu yang diperoleh pada kolam pembesaran berkisar antara 28-29 ${ }^{\circ} \mathrm{C}$. Hasil tersebut adalah rentang pengukuran suhu yang dilakukan selama 40 hari. Sedangkan $\mathrm{pH}$ yang didapat saat penelitian ini berkisar antara 6.5-7.8. Untuk DO rata-rata 5,0 ppm dan salinitas 32 ppt. Berikut hasil data pengamatan dan perbandingan menurut Arrokhman et al. (2012) disajikan dalam Tabel 2.

Tabel 2. Data hasil pengamatan kualitas air.

\begin{tabular}{ccc}
\hline Parameter & $\begin{array}{c}\text { Kisaran Optimal } \\
\text { (Arrokhman } \text { et al., 2012) }\end{array}$ & $\begin{array}{c}\text { Hasil Pengukuran di Lapang } \\
\text { (BPBL Lombok) }\end{array}$ \\
\hline Suhu & $28^{\circ} \mathrm{C}-30^{\circ} \mathrm{C}$ & $29^{\circ} \mathrm{C}$ \\
DO & $4,0-5,0 \mathrm{ppm}$ & $5,0 \mathrm{ppm}$ \\
Salinitas & $32 \%_{\mathrm{o}}-34 \%$ o & $32 \%_{0}$ \\
pH & $7,77-8,2$ & 7,8 \\
\hline
\end{tabular}

\section{Panen}

Benih bawal bintang yang siap dipanen yaitu berukuran 3-5 cm sesuai dengan permintaan konsumen. Jumlah keseluruhan total yang dipanen berjumlah $36,7 \mathrm{~kg}$ dengan berat rata-rata ikan 2,1 gram. Sebelum dilakukan packing, benih terlebih dahulu dipuasakan selama 12-24 jam tergantung pada jarak yang akan ditempuh. Jumlah Benih yang dipanen ditunjukkan pada Tabel 3.

Benih yang akan dipanen terlebih dahulu di grading untuk menentukan berapa ukuran dan menghitung stok benih, pada saat di grading benih juga dihitung untuk menentukan tingkat kelulushidupan.

Tabel 3. Jumlah benih yang dipanen.

\begin{tabular}{cc}
\hline Ukuran $(\mathrm{cm})$ & Jumlah (ekor) \\
\hline 5 & 7600 \\
4 & 5400 \\
3 & 4500 \\
Cacat & 350 \\
Total & 17.850 \\
\hline
\end{tabular}




\begin{abstract}
Pemasaran
Kegiatan pemasaran mencakup proses pengepakan dan pengangkutan benih. Proses transportasi benih dapat dilakukan dengan dua cara yaitu transportasi terbuka dan tertutup. Transportasi benih sistem terbuka digunakan untuk jarak dekat sedangkan transportasi benih sistem tertutup digunakan untuk jarak jauh.
\end{abstract}

\section{KESIMPULAN DAN SARAN \\ Kesimpulan}

Dari hasil penelitian tersebut dapat di simpulkan bahwa pembenihan ikan bawal bintang dengan menggunakan pakan tambahan rotifera merupakan suatu teknik pembenihan guna untuk mengefisiensikan hasil produksi.

\section{Saran}

Pada hasil penelitian memang pakan alami rotifera dapat menekan angka produksi yang tinggi karena dibudidayakan dengan skala masal. Masih ada kelemahan yang didapatkan pada penelitian ini yaitu pada masa panen ikan meskipun keuntungan sangat tinggi. Ikan bawal bintang menggunakan pakan pelet dapat dipanen pada umur 30-35 hari, tetapi dengan pemberian pakan rotifera ikan bawal bintang perlu mencapai masa panen hingga 50 hari.

\section{DAFTAR PUSTAKA}

Arrokhman, S., Abdulgani, N. dan Hidayati, D., 2012. Survival Rate Ikan Bawal Bintang (Trachinotus blochii) dalam Media Pemeliharaan Menggunakan Rekayasa Salinitas. Jurnal Sains dan Seni ITS.1 (1) : 32-35.

Fahmawati, Y., 2014. 20 Jenis Budidaya Perikanan Laut. Mitra Edukasi Indonesia. Bandung. $72 \mathrm{hlm}$.

Gopalakrishnan, A., 2014. Farming of Silver Pompano Trachinotus blochii in Coastal Aquaculture Ponds. Central
Marine Fisheries Research Institute (CMFRI) Pamphlet No: 22.

Juniyanto, N.M., S. Akbar dan Zakimin, 2008. Breeding and Seed Production of Silver Pompano (Trachinotus blochii, Lacepede) at The Mariculture Development Center of Batam. Marine Fish Aquaculture Network. hal. 46-49.

Lubzens E., Kolodny, G., Perry, B., Galai, N., Sheshinski, R. and Wax, Y., 1990. Factors affecting survival of rotifers, Brachionus plicatilis O.F. Mullerat $4^{\circ} \mathrm{C}$. Aquaculture, 91 (1): 186-203

Rachmasari, 1989. Studi pertumbuhan rotifer (Brachionus plicatilis) dengan pakan Chlorella sp., Tetraselmis dan ragi roti. Fak. Perikanan, Institut Pertanian Bogor : $72 \mathrm{pp}$. 